\title{
The Impact of the Application of Lexical Approach on Developing Students' Writing Skills at a University Level
}

\author{
Hassan Basil Abdulqader, (MA in Applied Linguistics) \\ Ivan Hasan Murad, (MA in TESOL) \\ Marwah Ihsan Abdulghani, (MA in Applied Linguistics) \\ Department of English Language, School of Humanities, \\ University of Zakho, Kurdistan Region, Iraq
}

Doi: 10.19044/esj.2017.v13n32p130 URL:http://dx.doi.org/10.19044/esj.2017.v13n32p130

\begin{abstract}
This paper aims at investigating experimentally the effect of applying the Lexical Approach (henceforth LA) on the achievement of third-year University students of English in the cause and effect essay writing. It examines theoretically and practically the LA and the notion of lexical units in English along with explaining some other relevant points. The two groups, pre-test and post-test experimental design were adopted to ensure groupmatching control over the intervening variables. After six weeks of instruction based on the LA, the results revealed that the experimental group had statistically significant gain scores between their pretests and posttests in the essay-writing test. The control group, however, did not have statistically significant gain scores on the dependent measure. The LA was beneficial to the third-year students. Consequently, the major findings validated the hypothesis of the study. In view of the findings obtained, application of the LA has been recommended and a number of pedagogical implications have been presented.
\end{abstract}

Keywords: Lexical Approach, University Teaching, Essay Writing, Experimental Group, and Controlled Group

\section{The Statement of the Problem}

Teaching English essay writing at the third year in the Department of English, University of Zakho is still structurally based. The learners are required to manipulate grammatical structures using a limited number of vocabulary items. Besides, while writing, they attempt to translate their mother tongue chunks literally into English. As a result, their writings turn 
out mostly to be odd if not grammatically wrong. Accordingly, the research question is crystalized in the following way: Does applying the methodology of the LA help in better achievement in essay writing classes as opposed to the currently used method of teaching?

\section{Hypothesis}

Based on the research question mentioned above and the related literature, it is hypothesized that the lexical approach can have a favorable effect on third year students' achievement in English essay writing at University level.

\section{Aim of the Study}

The aim of the present study is to verify the hypothesis already posed and to provide research-based answer to the question already raised. This study adopts applying the methodology of the LA to increase students' proficiency in the cause and effect essay writing in EFL classrooms at University level.

\section{Literature Review Introduction}

At the turn of the twentieth century, interest in vocabulary teaching and research increased. Diverse studies have revealed new understanding of how English language works leading to new descriptions of it, such as "Corpora Studies". Corpus investigations of natural language data have resulted in major changes in the way language is viewed. Using specially developed software, researchers have discovered frequently recurring multiword lexical chunks in texts, indicating that language is more repetitive than assumed (Biber et al., 1999; Cortes, 2004; Sinclair, 1991). According to Lewis (2000), corpora studies analyze English in depth; they provide us with new descriptions of English and improve it as a result of the analysis of large amounts of natural spoken and written texts on computers. Furthermore, a large number of corpora studies have revealed that lexis has a far more central role in the organization of language and the creation of meaning than was generally previously conceived (O'Keeffe et al, 2007).

Recent research in second language acquisition finds that language is mainly stored and retrieved as chunks and word combinations, i.e., collocations, binomials, phrases and sometimes sentences. e.g. 'commit a crime', 'raise a question', 'day and night', 'up and down', 'prons and cons', 'put an end to', 'compared with', 'I don't know', 'can I help you?', 'could I leave a message?, please', etc. The LA, in turn, aims at raising learners' awareness of these chunks. This could facilitate more natural language use and helps students to perform better in exams and more importantly be able to 
communicate in that language. In order to achieve this, students need a critical mass of chunks to get them over the threshold of the foreign language. Once the students get used to different chunks that fit different situations, they could be able to communicate effectively and appropriately, and this is what the present study attempts to investigate. That is why Lewis (2000) insists on teaching lexical chunks and giving them a top priority in every language course. Therefore, it is a way of learning language through words and groups of words that usually go together.

\section{The Lexical Approach (LA)}

The LA is a method of teaching a foreign language developed by Michael Lewis in the 1990s. This approach has received interest in recent years as an alternative to form-based approaches. It concentrates on developing learners' proficiency through lexis, words and word combinations. It is based on the assumption that an important part of language acquisition involves the ability to comprehend and produce lexical phrases as unanalyzed wholes, or chunks and that these chunks become the raw data by which learners perceive patterns of language traditionally thought of as grammar (Lewis, 2002).

\section{Principles of the $\mathrm{LA}$}

Lewis (2002, pp. vi-vii) identifies the following principles of the LA:

1. Language consists of grammatical lexis, not lexicalized grammar. i.e., the building blocks of language are lexis, not grammar.

2. Instructions need to ensure that learners focus predominantly on meaning. When we learn a language naturalistically, we do so by focusing primarily on what we want to say (i.e., meaning) rather than on how we say it (i.e., form).

3. The grammar/vocabulary dichotomy is invalid; much language consists of multi-word 'chunks'.

4. A central element of language teaching is raising students' awareness of, and developing their ability to 'chunk' language successfully.

5. Collocation is integrated as an organizing principle within syllabuses.

6. Evidence from computational linguistics and discourse analysis influence syllabus content and sequence.

7. Successful language is a wider concept than accurate language.

8. The primacy of speech over writing is recognized and writing is acknowledged as a secondary encodement, with a radically different grammar from that of the spoken language.

9. Task and process, rather than exercise and product are emphasized.

10. Receptive skills, particularly listening, are given enhanced status. 


\section{Types of Lexical Units}

The role of lexical units has been stressed in both first and second language acquisition research. Also, several linguists have suggested different taxonomies. For example Lewis (2002, pp. 91-94) suggests the following taxonomy of lexical items:

- $\quad$ Words (e.g. Book, pen).

- $\quad$ Polywords (e.g. By the way, upside down).

- Collocations or word partnerships (e.g. Community service, absolutely convinced).

- Institutionalized utterances (e.g. I'll get it; we'll see; that'll do; If I were you...; would you like a cup of coffee?)

- $\quad$ Sentence frames and heads (e.g. That is not as ... as you think; The fact is that/ The suggestion/ problem/danger was ...) and even text frames (e.g. In this paper we explore... ; Firstly... ; secondly... ; Finally ...)

Richards and Rodgers (2001, p. 133) add that many other lexical units also occur in language. For example:

- Binomials: clean and tidy, back and froth, prons and cons, up and down.

- Trinomials: cool, calm and collected.

- Idioms: dead drunk, to run up a bill.

- $\quad$ Similes: as old as the hills.

- $\quad$ Connectives: finally, to conclude.

- $\quad$ Conversational gambits: Guess what!

These and other types of lexical units are thought to play a central role in learning and in communication.

\section{Applying the Lexical Approach}

The LA emphasizes the teaching of lexical phrases, with the dictionary as a learning resource rather than just a reference, and the identification of lexical chunks as a basic classroom activity. Accordingly, specific roles for teachers and learners are assumed in the LA. Lewis (Cited in Richards and Rodgers, 2001) suggests that teacher talk is a major source of learner input in demonstrating how lexical phrases are used for different functional purposes. Willis (1990 cited in Richards and Rodgers, 2001) views the teacher's role as one of creating an environment in which learners can operate effectively and then helping learners manage their own learning. This requires that teachers abandon the idea of the teacher as 'knower' and concentrate instead on the idea of the learner as 'discoverer'.

Willis also notes that the computer analyses of texts indicate that "the 700 most frequent words of English account for around 70\% of all English 
text" (ibid). This 'fact' led to the decision that word frequency would determine the contents of the course.

However, it is not possible or even desirable to attempt to teach unlimited number of lexical chunks, but it is beneficial for language learners to gain exposure to lexical chunks and to gain experience in analyzing those chunks in order to begin the process of internalization. Willis adds that encouraging learners to notice language, specifically lexical chunks and collocations, is central to any methodology connected to a lexical view of language (Schmitt, 2000).

\section{Previous Studies}

The recent research on native speakers' fluency by computer driven analysis has concluded, "Fluency is based on the acquisition of a large store of fixed and semi-fixed prefabricated items" (Lewis, 1997,p.15). He named these items lexical chunks. A significant proportion of what English native speakers say and write consists of these lexical chunks (ibid). A number of studies have been conducted in this concern. For example, Nattinger and DeCarrico (1992) conducted their study on lexical chunks and pointed out that fluency is based precisely on these chunks. Lexical chunks offer ready access to social interactions and provide easily retrievable frame for actual communication. Cortes (2004) examined the use of lexical chunks in university classroom teaching and textbooks. He argued that these lexical chunks are stored as unanalyzed units in the mental lexicon and serve as building blocks for constructing discourse. Other studies have also shown that formulaic expressions are processed more quickly than no formulaic ones (Conklin \& Schmitt, 2008; Jiang \& Nekrasova, 2007). This implies that the former are likely to be stored mentally as single lexical units. Ying (2006) conducted a study to explore a more practical way to acquire fluency in English through teaching lexical chunks. He concluded that this way of teaching at least assists students in assimilating "real" English. He added that it opens up the possibility of altering present language teaching and provides the momentum to reach English fluency. In another study, Ilyas and Salih (2011) investigated experimentally the effect of using the LA on the achievement of second-year-university students of English in composition writing. They found that it was beneficial to second-year students.

These characteristics of lexical chunks can allow their use to have favorable influences on learners' writing processes. Howarth (1998) said that L2 failure to use native-like formulaic sequences is one factor in making their writing feel nonnative. Coxhead and Byrd (2007) noted that a type of discourse, such as academic writing, is characterized by certain vocabulary and grammar and that teachers can therefore; learn to identify the language that their students need to learn. For this reason, language learners can easily 
concentrate on these prefabricated chunks and try to memorize and use them as whole units in writing, which could free their cognitive resources during the writing process. In one study, various types of lexical chunks were found to constitute $52.3 \%$ of the written discourse investigated (Erman \& Warren, 2000). The absence of such chunks may indicate the lack of mastery of a novice writer in a specific disciplinary community (Haswell, 1991; Hyland, 2008).

Snellings, van Gelderen, and de Glopper (2004) tested whether fluency in lexical retrieval would lead to improvements in the quality of narrative L2 writing. Their argument was that increasing fluency in lexical retrieval would decrease cognitive efforts in L2 writing, which in turn would allow learners to use the additional attentional resources to focus on other processes, such as planning and organization. Milton (1998) claims that list-based instruction of lexical chunks (or what he called idiomatic expressions, such as all in all and in a nutshell) and rote learning for exam preparation in Hong Kong high schools leads to a substantial overuse of such phrases by Chinese L2 writers in academic writing.

Concerning a cause and effect essay, Flowerdew (1998) investigated discrepancies in the use of cause/effect markers (e.g., result from, arise from, account for, due to) between native professional writers and Cantonese advanced L2 learners by comparing a native speaker academic corpus and a Hong Kong learners' writing corpus. The results revealed that Hong Kong students tend to rely on a small group of causative conjunctions, whereas they severely underuse causative verbs, prepositions, and adjective sequences (e.g. responsible for, as a result of, result in, lead to) compared to the native speakers in the academic corpus. Learning lexical chunks as single lexical units can therefore ease the writing process, freeing up learners' cognitive resources by treating longer units of words as single lexical units. Thus, learning to write well also entails learning to use these lexical chunks appropriately. It has been generally agreed that chunks like (as a result and it should be noted that) are central to the creation of academic texts (Coxhead \& Byrd, 2007; Hyland, 2008).

In sum, all of these studies indicate, in a way or in another, to the importance of adopting the LA as well as the notion of lexical units, which is a main part of the LA. In addition, that the mastery of these two elements are crucial to create successful academic writers. Another point is that all of the mentioned studies focused primarily on the effect of lexical units in developing students' interactional and writing ability. Whereas, only one study adopted the LA to improve composition writing which is Ilyas and Salih (2011). However, up to date, according to the researchers' knowledge, there is no single attempt to adopt the LA to teach a cause and effect essay. Therefore, current research is trying to fill this gap. 


\section{Methodology}

In the following part, the information regarding the participants, study method, materials and procedures is presented.

\section{Participants}

The participants of the study consisted of 80 third-year students at the Department of English, College of Arts, University of Zakho for the academic year 2016-2017; 40 in the experimental group (henceforth EG) and 40 in the control group (henceforth CG). The students have already been exposed equally to various techniques and principles of writing a cause and effect essay. In other words, they know about the necessary requirements for writing an accurate and academic English essay.

\section{Applying the Experiment}

Before applying the experiment, the researchers made a number of meetings with the instructor who was going to implement the experimental lesson series in order to acquaint her with the aim of the study and the procedure to be followed when teaching the experimental group. The experiment lasted six weeks. Both groups had the same material which was a selection of cause and effect essays from the net. For example, (Why Cities are Overcrowded, The Effect of Smoking, The Effects of Telling Lies, etc). The only difference is that the plan for teaching writing to the EG was set according to the LA, while the plan for teaching writing to the CG was set according to the currently used method.

The experiment started on January $8^{\text {th }}$ and ended on February $16^{\text {th }}$, 2017. The pre-test consisted of one question in which the participants were asked to write a cause and effect essay of not less than 250 words on "Why Cities are Overcrowded?" The researchers carried out the pretest in class under the supervision of the teacher in order to make sure that the students do it themselves. After the test, all the essays were collected and graded by two specialized scorers who followed the same criteria. The researchers adopted the Jacobs et al. (1981) rubric, which is the most widely used and agreed on rubric for scoring non-native essay writing. This rubric contains five components: (1) content, (2) organization, (3) vocabulary, (4) language use and (5) mechanics. Each component has a four level score corresponding to four sets of criteria. The total score is out of (100). The average scores between the two scorers were the ultimate scores. After that, their scores were collected and analyzed.

During the six-weeks experiment, the students were identified with the notion of the LA and the different types of lexical units. They were also asked to concentrate on these lexical units whenever they watch TV., listen to radio, read a book or a magazine, etc. Keeping a lexical notebook to write the most 
beneficial phrases that the students may need in writing was a basic part of the experiment. While inside the classroom, prior to the writing process, usually at each class the students were presented with a sample of a cause and effect essay. They were asked to identify the words and chunks that were beneficial to use later when asked to write a similar type of essay. The teacher also presented the students with many other phrases that commonly occur in the context of a cause and effect essay writing such as (There are three reasons why...; The first/ second/ third reason is that...; as a result; This is why most people... etc). It is thought that these chunks can help them in writing a good cause and effect essay. Finally, the students' essays were marked and evaluated. As mentioned earlier, the Jacobs et al. (1981) rubric was followed for scoring the students' essays. This rubric contains five components: content, organization, vocabulary, language use and mechanics. Each component has a four level score corresponding to four sets of criteria. The teacher usually commented on the essays, selected the best ones, and utilized them as models to be imitated by other students.

The post-test, on the other hand, also consisted of the same question they have already written about in the pretest in order to investigate the progress made specially in the EG after being exposed to the treatment. This also happened under the supervision of the teacher. After the test, all the essays were collected and graded by the two scorers according to the same criteria. The average scores between the two scorers were adopted. After that, the scores of the two classes were collected and analyzed and then the two results were compared to each other in order to find whether there was any significant improvement of the students' writing skills after conducting the experiment.

\section{Data Analysis}

Data from both the pre-test and post-test are collected and verified using the t-test for the two independent samples to investigate the level of significance in order to figure out whether or not the differences between the two groups were statistically significant so that the hypothesis assumed earlier could be tested.

\section{Findings}

The raw scores of the pre-test were statistically computed using the ttest for the two independent samples. The mean scores, standard deviation and the $\mathrm{T}$ calculated are shown in Table 1. 
Table 1: The Mean, Standard Deviation, and

“t” Value of the Participants' Achievement Scores in the Pretest

\begin{tabular}{|c|c|c|c|c|c|c|c|}
\hline \multicolumn{9}{|c|}{ Group Statistics } & \multicolumn{2}{|c|}{ T value } \\
\hline \multirow{3}{*}{ Pretest } & Groups & $\mathrm{N}$ & Mean & $\begin{array}{c}\text { Std. } \\
\text { Deviation }\end{array}$ & $\begin{array}{c}\text { Std. Error } \\
\text { Mean }\end{array}$ & calculated & Tabulated \\
\cline { 2 - 7 } & $\begin{array}{c}\text { Control Group } \\
\text { Experimental } \\
\text { Group }\end{array}$ & 40 & 63.78 & 8.598 & 1.359 & & 0.33 \\
& 40 & 63.00 & 6.786 & 1.073 & -0.98 & $(80)(0.05)$ \\
\hline
\end{tabular}

The table above clearly shows that the difference between the CG and the EG was not statistically significant. This is evident from the calculated tvalue that was smaller than the tabulated $t$-value under 80 degrees of freedom and at 0.05 level of significance. The results also indicated that both groups roughly had the same background knowledge and English language proficiency.

A comparison was also made between the post-test scores of the CG and the EG. The aim was to see whether the difference was or was not statistically significant. The raw scores of the post-test were statistically computed using the t-test for the two independent samples. The mean scores, standard deviation and the $\mathrm{T}$ calculated are shown in Table 2.

Table 2: The Mean, Standard Deviation, and

" $t$ " Value of the Participants' Achievement Scores in the Posttest

\begin{tabular}{|c|c|c|c|c|c|c|c|}
\hline \multicolumn{9}{|c|}{ Group Statistics } & \multicolumn{2}{|c|}{ T value } \\
\hline & Groups & $\mathrm{N}$ & Mean & $\begin{array}{c}\text { Std. } \\
\text { Deviation }\end{array}$ & $\begin{array}{c}\text { Std. Error } \\
\text { Mean }\end{array}$ & Calculated & Tabulated \\
\hline \multirow{2}{*}{ posttest } & $\begin{array}{c}\text { Control } \\
\text { Group }\end{array}$ & 40 & 72.00 & 5.054 & .799 & & \\
\cline { 2 - 8 } & $\begin{array}{c}\text { Experimental } \\
\text { Group }\end{array}$ & 40 & 81.73 & 7.939 & 1.255 & 6.33 & $\begin{array}{c}0.33 \\
(80)(0.05)\end{array}$ \\
\hline
\end{tabular}

As shown in the table above, it is clear that the computed $\mathrm{T}$ value under the same degree of freedom and at 0.05 of significance shows a significant difference in the mean scores of the post-test in favour of the experimental group taught according to the LA.

\section{Discussion of the Results}

Based on the data and the findings obtained, one can argue that the LA is effective and easily applicable to students at the college level. Foreign language learners need to broaden their lexical units to express themselves more clearly and appropriately in the academic essay writing, a cause and effect essay in our case. The students in the EG were able to produce more natural language than the students in the CG. They were able to write more coherent and effective essays using the lexical units they learnt. Students used 
these lexical units even without knowing that they were doing so. These results also show that the control subjects' weakness in the final test is due to the fact that they were not able to produce lexical units or to use them in a particular context. Instead, they created odd sentences, though grammatically correct.

Even if they used a correct lexical unit, they were not able to use these lexical units properly in the right context. Thus, adopting the LA makes it easier for them to overcome such problems as well as improving their ability in the academic writing process. Now the answer to the research question (Does applying the methodology of the LA help in better achievement in essay writing classes as opposed to the currently used method of teaching?) which is already addressed is yes; The LA for teaching essay writing at college level did help in developing the learners' conversational skill. Consequently, the hypothesis of the present study which reads: "The LA can have a favorable effect on third year students' achievement in English essay writing at university level is confirmed".

\section{Conclusion}

The role of lexical units in language learning and communication has been enhanced by lexical and linguistic theory and by work in corpus analysis. The study reveals the importance of applying the LA in the classroom. It shows EFL teachers and learners a successful attempt of how to use lexical units as well as clear explanations of the importance of doing so. This study provides an accessible introduction for those new to this approach and guidance for those seeking to enhance their understanding and classroom implementation of the approach. It reinforces the importance of word combination patterns in language and their use in teaching and learning a language. Students may learn lexical units as they are reading a book, watching a movie, listening to radio, etc. Teachers can also give lists of different types of lexical units to students as they come up in class. The LA proves to improve students' essay writing skills and their accuracy of using related lexical units. Finally, much work must be done in Iraq to integrate this approach into the mainstream EFL course books.

\section{Recommendations}

In order to adopt the LA, the following recommendations are sound:

a) Teachers should integrate different types of lexical units instruction into the writing activities.

b) They should also raise students' awareness of these lexical units.

c) They should not overload students but search for usefulness.

d) Students are advised to keep written records of the different types of lexical units whenever they listen to native speakers, such as listen to the radio, watch TV, read books or magazines...etc. 


\section{References:}

1. Biber, et al. (1999). Longman Grammar of Spoken and Written English. Harlow: Longman, 41.

2. Conklin, K., \& Schmitt, N. (2008). Formulaic sequences: Are they processed more quickly than no formulaic language by native and nonnative speakers? Applied Linguistics, 29, 1-18.

3. Cortes, V. (2004). Lexical bundles in published and student disciplinary writing: Examples from history and biology. English for Specific Purposes, 23, 397-423.

4. Coxhead, A., \& Byrd, P. (2007). Preparing writing teachers to teach the vocabulary and grammar of academic prose. Journal of Second Language Writing, 16, 129-147.

5. Erman, B., \& Warren, B. (2000). The idiom principle and the openchoice principle. Text, 20, 29-62.

6. Flowerdew, L. (1998). Integrating 'expert' and 'interlanguage' computer corpora findings on causality: Discoveries for teachers and students.English for Specific Purposes, 17, 329-345.

7. Haswell, R. (1991). Gaining ground in college writing: Tales of development and interpretation. Dallas, TX: Southern Methodist University Press.

8. Howarth, P. (1998). The phraseology of learners' academic writing. In A. P. Cowie (Ed.), Phraseology: Theory, analysis, and applications (pp. 161-186). Oxford: Oxford University Press.

9. Hyland, K. (2008). As can be seen: Lexical bundles and disciplinary variation. English for Specific Purposes, 27(1), 4-21.

10. Jiang, N., \& Nekrasova, T. N. (2007). The processing of formulaic sequences by second language speakers. The Modern Language Journal, 91, 433-445.

11. Ilyas, O. A. and Salih, F. M. (2011). Teaching EnglishComposition Writing at College Level. Journal of Education and Science, 18, 217233.

12. Lewis, M. (1997). Implementing the Lexical Approach: Putting Theory into Practice. London: Heinle, Cengage Learning.

13. ........... (2000). Teaching Collocation: Further Development in the Lexical Approach . London: Language Teaching Publications.

14. ........... (2002). The Lexical Approach: The State of ELT and a way Forward . London: Heinle, a part of the Thomason Corporation.

15. Milton, J. (1998). Exploiting L1 and interlanguage corpora in the design of an electronic language learning and production environment. In S. Granger (Ed.), Learner English on computer (pp. 186-198). London: Longman 
16. Nattinger, J. and DeCarrico, J. (1992). Lexical Phrases and Language Teaching. Oxford: OUP.

17. O'Keeffe, A., McCarthy, M. and Carter, R. (2007). From Corpus to Classroom: Language Use and Language Teaching. Cambridge: CUP.

18. THROUGH TEACHING LEXICAL PHRASES. CELEA Journal. 29, 43-47.

19. Richards, J. C. \& Rodgers, T. S. (2001) Approaches and Methods in Language Teaching ( $2^{\text {nd }}$ ed). Cambridge: Cambridge University Press.

20. Sinclair, J. (1991). Corpus, concordance, collocation. Oxford: Oxford University Press.

21. Snellings, P., van Gelderen, A., \& de Glopper, K. (2004). The effect of enhanced lexical retrieval on second language writing: A classroom experiment. Applied Psycholinguistics, 25, 175-200.

22. Ying, L. (2006) A CONSIDERATION OF PROMOTING ENGLISH FLUENCY 